\title{
Характеризация кристаллического совершенства слоев гетероструктур (013)HgCdTe/CdTe/ZnTe/GaAs методом генерации второй гармоники
}

\author{
С.А. Дворецкий ${ }^{1,4}$, М.Ф. Ступак ${ }^{2}$, Н.Н. Михайлов ${ }^{1,3}$, С.Н. Макаров ${ }^{2}$, А.Г. Елесин ${ }^{2}$, А.Г. Верхогляд ${ }^{2}$ \\ ${ }^{1}$ Институт физики полупроводников СО РАН), Новосибирск, 630090, пр. Акад. Лаврентьева, 13 \\ ${ }^{2}$ Конструкторско-технологический институт научного приборостроения СО РАН, \\ Новосибирск, 630058, Русская, 41 \\ ${ }^{3}$ Новосибирский государственный университет (НГУ), Новосибирск, 630090, Пирогова, 2 \\ ${ }^{4}$ Томский государственный университет (ТГУ), 634050, Томск, пр. Ленина, 36 \\ тел.: +7(383) 330-4967, факс:+7(383)330-4967, эл. почта: dvor@isp.nsc.ru
}

DOI 10.34077/RCSP2021-75

Представлены результаты по исследованию структурного состояния и его изменениям в гетероструктурах (013)HgCdTe/CdTe/ZnTe/GaAs, выращенных методом МЛЭ, с помощью генерации второй гармоники (ГВГ). Метод ГВГ является одним из наиболее эффективных, экспрессных и чувствительных методов неразрушающего оптического контроля фазово-структурных свойств приповерхностных слоев данных структур [1]. Осуществлена модернизация стенда нелинейнооптической диагностики, что позволило более чем на порядок снизить шумы и, тем самым, повысить чувствительность. Это было достигнуто в основном за счет частотной селекции и усиления полезного сигнала после фотоумножителя. Для анализа экспериментальных результатов азимутальных зависимостей ГВГ проводилось сравнение с расчетными данными, полученными при численном моделировании идеального кристалла для заданной ориентации (013). Толщина лазерного луча для ГВГ составляла $\sim 200$ мкм. Были проведены исследования структурного состояния подложек GaAs, буферных слоев CdTe на подложке $\mathrm{ZnTe} / \mathrm{GaAs}$ и $\mathrm{CdxHg} 1$-хТе на подложке $\mathrm{CdTe} / \mathrm{ZnTe} / \mathrm{GaAs}$. Толщины буферных слоев $\mathrm{d}_{\mathrm{ZnTe}} \approx 30$ нм и $\mathrm{d}_{\mathrm{CdTe}} \approx 5,5$ мкм. Слои КРТ были варизонными на гетерограницах с плавно изменяющимся составом $\mathrm{X}_{\mathrm{CdTe}}$ от 0,45 до рабочего $0,22:$ толщина $\mathrm{dвap} \mathrm{н} \approx 1,5$ мкм, толщина рабочего состава $\mathrm{dKPT} \approx 6$ мкм и от рабочего слоя к поверхности $\mathrm{dвар} \mathrm{в} \approx 0,5$ мкм.

Напряжения в подложке и слоях проявлялись по наличию на экспериментальных графиках ГВГ ярко выраженной асимметрии минимумов азимутальной зависимости и изменения их уровней по сравнению с идеальным кристаллом. Было определено, что подложка и слои в гетероструктуре имеют остаточные напряжения. При выращивании эпитаксиальных слоев на вицинальных поверхностях подложки наблюдается разворот плоскости ориентации от плоскости подложки, что обычно определяют с помощью рентгеновской дифрактометрии. Разворот плоскости (013) для слоев CdTe составил от 3 до 8 угловых градусов. Было проведено исследование разворота слоев $\mathrm{HgCdTe}$ при послойном стравливании. Наблюдалось немонотонное изменение разворота слоев по толщине. Последовательно, в варизонном слое на гетерогранице с подложкой $\mathrm{CdTe} / \mathrm{ZnTe} / \mathrm{GaAs}$ paзворот плоскости продолжал увеличиться быстрее, чем в слое постоянного состава, и уменьшался в варизонном слое на поверхности. Было замечено увеличение шума экспериментальных графиков азимутальной зависимости ГВГ от структуры слоев $\mathrm{HgCdTe}$ при травлении, превышающее уровень шумов всего приборного тракта. Анализ результатов появления шума позволяет связать этот факт с присутствием слабо разориентированных конгломератов.

Зарегистрированная большая амплитуда сигнала ГВГ от $\mathrm{HgCdTe}$ связана с большой величиной нелинейной восприимчивости $\chi_{x y z}(\omega)$, превосходящей более чем на порядок аналогичную величину для СdTе и GaAs.

Работа поддержана частично за счет средств гранта РФФИ № 18-29-20053 и в рамках ГЗ Минобрнауки России в части проекта АAАA-A20-120102190007-5.

\section{Лuтература}

[1] М.Ф. Ступак, Н.Н. Михайлов, С.А. Дворецкий, М.В. Якушев, Д.Г. Икусов, С.Н. Макаров, А.Г. Елесин, А.Г. Верхогляд. ФТТ, 62 (2), 214 (2020). 